\title{
\begin{tabular}{l|l} 
Mitraries & DSpace@MIT
\end{tabular}
}

\author{
MIT Open Access Articles
}

\section{Developing a Social Cost of Carbon for US Regulatory Analysis: A Methodology and Interpretation}

The MIT Faculty has made this article openly available. Please share how this access benefits you. Your story matters.

Citation: Greenstone, M., E. Kopits, and A. Wolverton. “Developing a Social Cost of Carbon for US Regulatory Analysis: A Methodology and Interpretation." Review of Environmental Economics and Policy 7, no. 1 (January 1, 2013): 23-46.

As Published: http://dx.doi.org/10.1093/reep/res015

Publisher: Oxford University Press

Persistent URL: http://hdl.handle.net/1721.1/85655

Version: Author's final manuscript: final author's manuscript post peer review, without publisher's formatting or copy editing

Terms of use: Creative Commons Attribution-Noncommercial-Share Alike 


\title{
Developing a Social C ost of C arbon for U.S. Regulatory A nalysis: A M ethodology and Interpretation*
}

\author{
Michael Greenstone \\ M assachusetts Institute of Technology and NBER \\ Elizabeth Kopits \\ U.S. Environmental Protection A gency \\ A nn W olverton \\ U.S. Environmental Protection A gency
}

* The authors thank Charlie K olstad, R obert K opp, A lex M artin, Steve N ewbold, R obert Stavins, Cass Sunstein, and two anonymous referees for insightful comments. The views expressed in this article are those of the authors and do not necessarily represent those of the U.S Environmental Protection A gency or the M assachusetts Institute of Technology. All three authors worked for 
the Council of Economic A dvisers in 2009 and/or 2010 and actively participated in the process to develop a social cost of carbon for the U nited States. 


\title{
Developing a Social C ost of C arbon for U.S. Regulatory A nalysis: \\ A M ethodology and Interpretation
}

\begin{abstract}
The U nited States Government recently developed a range of values representing the monetized global damages associated with an incremental increase in carbon dioxide $\left(\mathrm{CO}_{2}\right)$ emissions, commonly referred to as the social cost of carbon (SCC). These values are currently used in benefit-cost analyses to assess potential federal regulations. For 2010 , the central value of the SCC is $\$ 21$ per ton of $\mathrm{CO}_{2}$ emissions, with sensitivity analyses to be conducted at $\$ 5, \$ 35$, and $\$ 65$ per ton of $\mathrm{CO}_{2}(2007 \$)$. This article summarizes the methodology and interagency process used to develop these SCC values, offers our own commentary on how the SCC can be used to inform regulatory decisions, and identifies priorities for further research.
\end{abstract}

JEL Codes: Q54, Q51, and Q58

Keywords: climate change; social cost of carbon; integrated assessment modeling; valuation of environmental quality; U.S. climate policy 


\section{INTRODUCTION}

A few years ago, it seemed possible, perhaps even likely, that the United States and other major emitters of greenhouse gases (GHGs) would confront climate change by adopting a coordinated set of policies, including the possibility of linked cap-and-trade systems. However, given the failure of the United States to enact a domestic cap-and-trade system and the non-binding commitments of the 2009 Copenhagen A ccord, ${ }^{1}$ a global, coordinated solution to climate change appears to be out of reach for at least the next several years. Instead, the U nited States and many other countries are likely to pursue their own, more targeted policies to reduce GHG emissions, ranging from subsidies for the installation of low carbon energy sources to regulations requiring energy efficiency standards in buildings, motor vehicles, and even vending machines to rebates for home insulation materials. Individually, these policies are expected to have only a marginal impact on atmospheric concentrations of G HGs (Bianco et al. 2010).

Faced with numerous policy options to reduce GHG emissions, how is a government to identify those that are the most worthwhile? The key is to determine the monetized damages associated with an incremental increase in carbon emissions, generally referred to as the social cost of carbon (SCC). ${ }^{2}$ The SCC is intended to include (but is not limited to) changes in net agricultural productivity, human health, property damages from increased flood risk, and the value of ecosystem services. Monetized estimates of the economic damages associated with carbon

\footnotetext{
${ }^{1}$ The Copenhagen Accord is the outcome of the 2009 Copenhagen Climate Change Summit, at which more than two dozen key countries - accounting for more than 80 percent of the world's GHG emissions -- agreed to reduce their emissions and to register their national commitments by the end of J anuary 2010.

${ }^{2}$ It is important to note that the SCC described in this article is not intended to be used to estimate the benefits of policies such as coordinated global agreements that are expected to produce non-marginal reductions in GHG emissions.
} 
dioxide $\left(\mathrm{CO}_{2}\right)$ emissions make it possible for benefit-cost analyses to incorporate the social benefits of regulatory actions that are expected to reduce these emissions. As the U.S. Environmental Protection A gency (EPA) begins to regulate GHGs under the Clean Air Act and other agencies promulgate regulations aimed at reducing energy consumption, the SCC can help to identify regulations that have positive net benefits.

With these objectives in mind, the U.S. government established an interagency working group, composed of scientific and economic experts from the White House as well as the EPA, the Departments of A griculture, Commerce, Energy, and Transportation, and the Treasury Department, to develop a transparent and economically rigorous way to value the reductions in $\mathrm{CO}_{2}$ emissions that result from Federal regulations. ${ }^{3}$ Between 2009 and 2010, the working group developed four estimates of the global damages per ton of $\mathrm{CO}_{2}$ emissions, which have been used in regulatory impact analyses since their release (Interagency W orking Group 2010). The process that developed these SCC values was the first U.S. government effort to consistently calculate the social benefits of reducing $\mathrm{CO}_{2}$ emissions for use in the benefit-cost analysis of potential federal regulations. Previously, reductions in $\mathrm{CO}_{2}$ emissions were either not valued or the values that were employed varied substantially across agencies.

The interagency group developed the range of SCC values using three well-known integrated assessment models (IAM s), a range of socioeconomic and emissions scenarios, three discount rates, and a probability distribution for equilibrium climate sensitivity. For emission changes occurring in 2010, the central SCC value is $\$ 21$ per ton of $\mathrm{CO}_{2}$ emissions, with sensitivity analyses to be conducted at $\$ 5, \$ 35$, and $\$ 65$ (all values are in 2007 dollars per ton of $\mathrm{CO}_{2}$ ).

\footnotetext{
${ }^{3}$ The goal was to develop a range of SCC values that use a defensible set of input assumptions, are grounded in the existing literature, and reflect key uncertainties and model differences.
} 
These SCC estimates grow over time based on rates endogenously determined within each model. For instance, the central value increases to $\$ 26$ per ton of $\mathrm{CO}_{2}$ in 2020 .

This article summarizes the methodology used by the interagency working group to develop a range of SCC estimates for use in regulatory decision making (in many instances, borrowing language directly from the interagency report), discusses how these SCC estimates can be used to inform regulatory decisions, and identifies priorities for future research. ${ }^{4}$ W e note at the outset that developing estimates of the SCC requires making many assumptions and it is inevitable that some readers will not agree with all of them. Our aim here is to describe these assumptions in sufficient detail to enable readers to conduct their own research and suggest improvements so that future efforts to revise the SCC will rely on a methodology that improves on the one that is described here.

The article is organized as follows. The next section describes the three integrated assessment models used to estimate the SCC. This is followed by a discussion of the main modeling assumptions made by the interagency group. Next we describe how the interagency group calculated and then selected the SCC values. The following section summarizes the main limitations of IAM s and identifies priorities for future research. Conclusions are presented in the final section.

\section{INTEGRATED ASSESSMENT MODELSAND THEIR DAMAGE FUNCTIONS}

\footnotetext{
${ }^{4}$ The interagency report is available in full at http://www.whitehouse.gov/sites/default/files/omb/inforeg/foragencies/Social-Cost-of-Carbon-for-RIA.pdf.
} 
A nalysts face a number of challenges when attempting to estimate the economic consequences of $\mathrm{CO}_{2}$ emissions. In particular, it is necessary to make assumptions concerning the four main steps in the estimation process: (1) the future emissions of GHGs; (2) the effects of past and future emissions on the climate system; (3) the impact of changes in climate on the physical and biological environment; and, (4) the translation of these environmental impacts into economic damages. Researchers have developed integrated assessment models -- IAM s -- to combine these steps into a single modeling framework; the word "integrated" reflects the fact that these models combine insights drawn from both science and economics. However, the advantages of using a single, integrated framework are gained at the expense of a more detailed representation of the underlying climatic and economic systems.

The interagency group relied on three IA M s commonly used to estimate the SCC: the Dynamic Integrated Climate and Economy (DICE), the Policy A nalysis of the Greenhouse Effect (PAGE), and the Climate Framework for Uncertainty, Negotiation, and Distribution (FUND) models. ${ }^{5}$ Each of the three models is given equal weight in the SCC values developed by the interagency group. A number of simplifying assumptions and judgments underlie the three IA M s, reflecting the modelers' best attempts to synthesize the available scientific and economic research. A Ithough the framew orks of other IA M s may better reflect the complexity of the science, they do not link physical impacts to economic damages, an essential step for estimating the SCC.

\footnotetext{
${ }^{5}$ These models are frequently cited in the peer-reviewed literature and are used in the Fourth A ssessment Report of the Intergovernmental Panel on Climate Change (IPCC 2007). The DICE model was developed by William Nordhaus in 1990 (Nordhaus and B oyer 2000, N ordhaus 2008). The PA GE model was developed by Chris Hope in 1991 for use by European decision-makers (Hope 2006, Hope 2008) and underlies The Stern Review (Stern et al. 2006). The FUND model was developed by Richard Tol in the early 1990s (e.g., Tol 2002a, Tol 2002b, A nthoff et al. 2009, Tol 2009). The interagency group did not use the World Induced Technical Change Hybrid (WITCH) model (Bosetti et al. 2007), which is occasionally cited in the literature, although generally less frequently than DICE, PAGE, and FUND.
} 
DICE, PAGE, and FUND all take highly simplified (i.e., reduced-form) approaches to estimate the SCC (see NRC 2009 and Nordhaus 2008). They translate emissions into changes in atmospheric GHG concentrations, atmospheric concentrations into changes in temperature, and changes in temperature into economic damages. The baseline emissions projections are based on specified socio-economic (GDP and population) pathways. These emissions are translated into concentrations using the carbon cycle built into each model, and concentrations are translated into changes in temperature based on each model's simple representation of the climate and a key parameter, climate sensitivity. Finally, the effects of temperature change are monetized based on one or more functions that translate the physical impacts associated with temperature increase into economic damages and the discount rate that is used to convert the stream of economic damages over time into a single value.

\section{Mapping $C$ hanges in Temperature to $C$ hanges in $E$ conomic Damages}

Each model takes a somewhat different approach to modeling how changes in temperature are manifested as economic damages. In PAGE, damages are divided into three broad categories: economic, noneconomic, and catastrophic. The consumption-equivalent damages in each period are calculated as a fraction of GDP, depending on the temperature in that period relative to the pre-industrial average temperature in each region. In FUND, damages in each period also depend on the rate of temperature change from the previous period. Notably, this model estimates the damages separately for eight different market and nonmarket sectors: agriculture, forestry, water, energy, sea level rise, ecosystems, human health, and extreme weather. In DICE, temperature affects both consumption and investment. A lthough the model is calibrated to include the effects

of temperature changes on the production of market and nonmarket goods and services, these 
impacts are not estimated separately in the model. However, DICE does incorporate impacts on agriculture, coastal areas (due to sea level rise), energy use, human health, non-market amenities (based on outdoor recreation), and human settlements and ecosystems. Unlike the approach in FUND and PAGE, in DICE GDP is endogenous, which means that damages experienced in one year reduce GDP in future years. ${ }^{6}$

The PAGE and DICE damage functions also explicitly include the possibility of catastrophes at higher temperatures. PAGE models catastrophes probabilistically as a function of a threshold temperature, the rate at which the likelihood of a catastrophe increases above the threshold, and the magnitude of the resulting catastrophe. DICE includes the expected value of damages associated with low probability, high impact "catastrophic" climate change. FUND does not explicitly include catastrophic damages.

M oreover, as we will discuss next, in estimating the SCC the interagency group chose to treat climate sensitivity (i.e., the temperature change associated with a given change in atmospheric concentrations of $\mathrm{CO}_{2}$ ) probabilistically, which preserves the influence of nonlinearities in the damage functions.

\section{Accounting for Adaptation}

The three models vary widely in how they account for compensatory adjustments, or adaptation, in response to climate change, which will mitigate the negative impacts on wellbeing. FUND allows for induced adaptation in certain sectors. PAGE assumes adaptation reduces climate impacts, but it is imposed exogenously. For instance, PA GE assumes that developed countries

\footnotetext{
${ }^{6}$ Since DICE allocates economic output net of climate damages to consumption and investment, reduced damages in early periods due to mitigation action by other countries can lead to increased economic output (and hence increased absolute damages) in later periods.
} 
can eliminate up to 90 percent of all economic impacts beyond a $2{ }^{\circ} \mathrm{C}$ increase and developing countries can eventually eliminate 50 percent of economic impacts. DICE does not account for adaptation explicitly, although it is included implicitly through the choice of studies used to calibrate the damage function. It is possible that the three models fail to adequately account for the various ways in which adaptation could occur. However, the evidence available on this issue is limited. Thus, the interagency group retained the modelers' assumptions in this regard.

\section{Damage Functions}

Figure 1 presents the damage functions for each IAM, based on the modeler's default scenarios and assumptions. The $x$-axis indicates increases in annual temperature in 2100 , while the $y$-axis indicates the annual consumption loss in 2100 as a share of global GDP. There are significant differences between models at both lower and higher increases in global average temperature, reflecting, in part, differences in assumptions about the rate of technological change and the ability of human and natural systems to adapt to the effects of climate change. ${ }^{7}$ The FUND damage function predicts that temperature increases up to about $3{ }^{\circ} \mathrm{C}$ are beneficial due to the combined effect of $\mathrm{CO}_{2}$ fertilization in the agricultural sector, positive impacts of higher temperature on some regions, and increases in temperature that are sufficiently slow to allow for adaptation (thus resulting in lower damages).

\footnotetext{
${ }^{7}$ Although not reflected in Figure 1 , it is worth noting that the models vary in what is treated probabilistically. In DICE, parameters are handled deterministically and represented by fixed constants. In contrast, in PAGE and FUND, most parameters are represented by probability distributions.
} 
Figure 1: Projected Annual C onsumption L oss as a Fraction of G lobal GDP in 2100 Due to an Increase in Annual G lobal Temperature:

DICE, FUND, and PAGE models

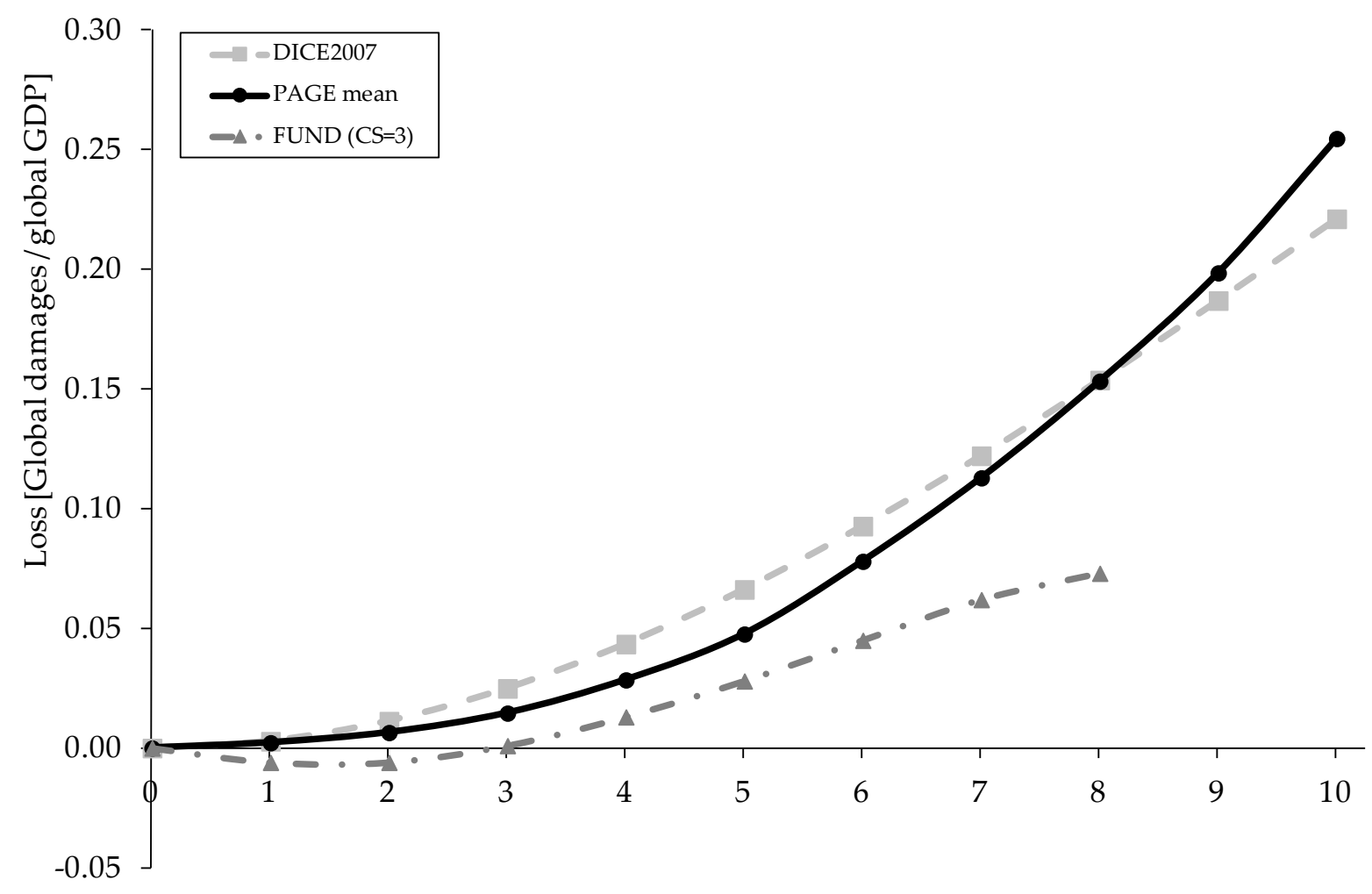

Temperature change $\lceil\operatorname{deg} \mathrm{C}\rceil$

Source: Figure 1A, Interagency report.

Notes: These damage functions reflect the default assumptions in each model; they reflect neither those interagency assumptions that differ from the default values nor the probabilistic treatment of parameters. 


\section{The Power and Limitations of IAMS}

Overall, the power of IAMs is that they offer some guidance concerning the complex issue of how an additional ton of GHGs will affect human wellbeing. Estimating these impacts is no small task and this is what makes these models so attractive to researchers. However, the results are highly dependent on assumptions (e.g., the rate of economic growth in different countries, when certain technologies will come online, how quickly societies can adapt to climate impacts) that cannot be easily verified. Indeed, the differences across the damage functions, as indicated by Figure 1, underscore the need for continued research aimed at improving how the models incorporate adaptation, technological change, and catastrophic damages. ${ }^{8}$

\section{KEY MODELING ASSUMPTIONS}

A key objective of the interagency process was to develop a methodology for exploring and assessing the SCC using each of the three IAM s in a way that was consistent and comparable while respecting the modelers' different approaches to quantifying damages. With this in mind, the interagency group conducted an extensive review of the literature and identified three key input parameters -- socio-economic and emissions trajectories, climate sensitivity, and discount rates -- that were held fixed across the three models. All other model features were left unchanged, thus relying on the modelers' best estimates and judgments. This section discusses the assumptions made by the interagency group concerning these three key parameters as well as the group's decisions about how to address other important modeling issues.

\section{Socio-economic and E missions Trajectories}

\footnotetext{
${ }^{8}$ Later we discuss in more detail the models' limitations in accounting for various scientific and economic processes.
} 
Socio-economic pathways are closely tied to climate damages because, all else equal, more and wealthier people tend to emit more GHGs and al so have a higher (absolute) willingness to pay to avoid climate disruptions. For this reason, it is standard to model several variables in tandem: $\mathrm{GDP}$, population, $\mathrm{CO}_{2}$ emissions, and the warming impact of non- $\mathrm{CO}_{2} \mathrm{GHGs}$. To determine which scenarios to use as inputs in the analysis, the interagency group examined a plausible range of outcomes for these variables, with the aim of developing estimates of the damages associated with the marginal changes in emissions from these scenarios.

The Stanford Energy M odeling F orum Scenarios

To derive the socio-economic and emissions pathways in a transparent manner, the interagency group relied on the results of the Stanford Energy M odeling Forum exercise, EM F-22. ${ }^{9}$ A key advantage of relying on these data is that the GDP, population, and emission trajectories are internally consistent for each scenario evaluated. However, a key disadvantage is that these data allowed for only a crude probabilistic accounting of the likelihood of future mitigation action by other countries.

Five trajectories were selected from EMF-22 to represent the socio-economic and emissions pathways (see Table 1), and all of the trajectories were given equal weight in the interagency group's derivation of the SCC. The first four trajectories represent business-as-usual (BAU) growth in population, wealth, and emissions and are associated with $\mathrm{CO}_{2}$ (only) concentrations ranging from 612 to 889 parts per million (ppm) in 2100 (although none of these four scenarios

\footnotetext{
${ }^{9}$ The Energy M odeling Forum (EM F) is an international forum for sharing and facilitating discussions on energy policy and global climate issues among experts. Participating institutions from around the world are periodically brought together to examine a single topic to which many existing models can be applied. EM F-22 included analysis from 10 models of international climate change control scenarios.
} 
reaches stabilization by 2100). ${ }^{10}$ The fifth trajectory represents an emissions pathway that achieves stabilization at $550 \mathrm{ppm} \mathrm{CO}_{2}$ e (i.e., $\mathrm{CO}_{2}$-only concentrations of $425-484 \mathrm{ppm}$ ) in 2100 due to widespread mitigation by countries around the world. Since each socio-economic pathway is given equal weight, this scenario is assigned a 20 percent chance of occurring.

Table 1: G lobal Socioeconomic and E missions Projections from Five E M F-22 R eference Scenarios

\section{A. Fossil and Industrial $\mathrm{CO}_{2}$ E missions ( $\mathrm{GtCO}_{2} / \mathrm{yr}$ )}

\begin{tabular}{cccccc} 
& & & & \multicolumn{3}{c}{ A nnualized \% Change } \\
\hline EM F - 22 B ased Scenarios & 2000 & 2050 & 2100 & $2000-2050$ & $2050-2100$ \\
\hline IM A GE & 26.6 & 45.3 & 60.1 & $1.1 \%$ & $0.6 \%$ \\
\hline M ERGE Optimistic & 24.6 & 66.5 & 117.9 & $2.0 \%$ & $1.2 \%$ \\
\hline MESSA GE & 26.8 & 43.5 & 42.7 & $1.0 \%$ & $0.0 \%$ \\
\hline M iniCAM & 26.5 & 57.8 & 80.5 & $1.6 \%$ & $0.7 \%$ \\
\hline 550 ppm average* & 26.2 & 20.0 & 12.8 & $-0.5 \%$ & $-0.9 \%$ \\
\hline
\end{tabular}

\section{B. GDP per capita (using market exchange rates, 2005\$)}

\begin{tabular}{cccccc} 
& & & & \multicolumn{2}{c}{ A nnualized \% Change } \\
\hline EM F - 22 B ased Scenarios & 2000 & 2050 & 2100 & $2000-2050$ & $2050-2100$ \\
\hline IM A GE & 6,328 & 17,367 & 43,582 & $2.0 \%$ & $1.9 \%$ \\
\hline M ER GE Optimistic & 6,050 & 13,633 & 27,629 & $1.6 \%$ & $1.4 \%$ \\
\hline M ESSA GE & 6,246 & 16,351 & 32,202 & $1.9 \%$ & $1.4 \%$ \\
\hline M iniCA M & 6,017 & 14,284 & 42,471 & $1.7 \%$ & $2.2 \%$ \\
\hline 550 ppm average & 6,082 & 15,793 & 37,132 & $1.9 \%$ & $1.7 \%$ \\
\hline
\end{tabular}

\footnotetext{
${ }^{10}$ The 2100 concentrations are 889 ppm for M ERGE Optimistic, 612 ppm for MESSA GE, and 794 ppm for M iniCAM. The IMAGE 2100 concentration is not provided in the EM F data file.
} 


\section{Global Population (billions)}

\begin{tabular}{cccccc} 
& & & \multicolumn{3}{c}{ A nnualized \% Change } \\
\hline EM F - 22 B ased Scenarios & 2000 & 2050 & 2100 & $2000-2050$ & $2050-2100$ \\
\hline IM A GE & 6.1 & 9.0 & 9.1 & $0.8 \%$ & $0.0 \%$ \\
\hline M ERGE Optimistic & 6.0 & 9.0 & 9.7 & $0.8 \%$ & $0.1 \%$ \\
\hline MESSA GE & 6.1 & 9.4 & 10.4 & $0.9 \%$ & $0.2 \%$ \\
\hline M iniCAM & 6.0 & 8.8 & 8.7 & $0.8 \%$ & $0.0 \%$ \\
\hline 550 ppm average & 6.1 & 8.7 & 9.1 & $0.7 \%$ & $0.1 \%$ \\
\hline
\end{tabular}

Source: The socioeconomic scenarios are available at Stanford's Energy M odeling Forum: http://emf.stanford.edu/events/emf_briefing_on_climate_policy_scenarios_us_domestic_and_int ernational_policy_architectures/.

Notes: The models were calibrated from a 2000 base year.

* In the fifth scenario, 2000-2100 projections are equal to the average of the $550 \mathrm{ppm} \mathrm{C02e} \mathrm{stabilization}$ scenarios considered by each of the four models used to represent the BAU trajectories (IMAGE, MERGE Optimistic, MESSAGE, and M iniCA M ).

Caveats

A few caveats are in order. First, the EM F-22 BAU scenarios represent the modelers' judgment of a likely emissions pathway rather than the wider range of possible outcomes that could occur. Nevertheless, these views range from the more optimistic (e.g., abundant low-cost, low-carbon energy) to more pessimistic (e.g., constraints on the availability of nuclear and renewables). It is also worth noting that the emissions trajectories underlying some BAU scenarios (e.g., M ESSA GE) are consistent with modest policy action to address climate change.

Second, the $550 \mathrm{ppm}$ socio-economic trajectory is not derived from an assessment of what policy is optimal from a benefit-cost standpoint. Rather it represents the potential for aggressive 
mitigation efforts in the future. The interagency group chose not to include socio-economic trajectories that achieve GHG concentrations lower than $550 \mathrm{ppm}$ because many of the models that are included in the EM F-22 could not meet this target (i.e., they had difficulty converging).

Third, the approach used by the interagency group to specify the baseline scenarios does not account for some potentially important future scientific, economic, and policy changes and their dynamic influence on the models. For example, new evidence that leads scientists to revise the climate sensitivity or expected global temperature response to GHG accumulation in the atmosphere would require a change in the temperature forecasts in these IAMs. This new evidence might also lead to policy actions that either reduce or increase the stringency of GHG regulations, which would require a change in the emissions and temperature forecasts. Other forms of learning and policy responses could also change the SCC in the long run. Thus, it is important that the SCC values be re-estimated over time using updated assumptions about socioeconomic and emissions trajectories that reflect new information and new measures to reduce emissions.

\section{Equilibrium Climate Sensitivity}

Equilibrium climate sensitivity (ECS) is a key input parameter in DICE, PAGE, and FUND. It determines the speed and magnitude of temperature change for a given emissions path and is defined as the increase in the annual global-average surface temperature from a doubling of atmospheric $\mathrm{CO}_{2}$ concentration, relative to pre-industrial levels (or stabilization at a concentration of approximately $550 \mathrm{ppm})$. ECS reflects a relatively short to medium term 
response (100-200 years), as it does not include long-term feedback effects due to possible largescale changes in ice sheets or the biosphere that occur on a time scale of many hundreds to thousands of years (e.g., Hansen et al. 2007).

Uncertainties Concerning Climate Sensitivity

Uncertainties concerning this important parameter have received substantial attention in the peerreviewed literature (see e.g., Roe and Baker 2007). However, the most authoritative statement about ECS appears in the Fourth A ssessment Report of the Intergovernmental Panel on Climate Change (IPCC):

Basing our assessment on a combination of several independent lines of evidence... including observed climate change and the strength of known feedbacks simulated in [global climate models], we conclude that the global mean equilibrium warming for doubling $\mathrm{CO}_{2}$, or 'equilibrium climate sensitivity', is likely to lie in the range $2{ }^{\circ} \mathrm{C}$ to $4.5^{\circ} \mathrm{C}$, with a most likely value of about $3{ }^{\circ} \mathrm{C}$. E quilibrium climate sensitivity is very likely larger than $1.5^{\circ} \mathrm{C}$.

For fundamental physical reasons as well as data limitations, values substantially higher than $4.5^{\circ} \mathrm{C}$ still cannot be excluded, but agreement with observations and proxy data is generally worse for those high values than for values in the $2{ }^{\circ} \mathrm{C}$ to $4.5^{\circ} \mathrm{C}$ range. (M eehl et al., 2007, p 799)

Selection of ECS Distribution 
A fter consulting with several lead authors of the IPCC report, the interagency group considered four possible probability distributions to represent ECS. ${ }^{11}$ In each case, the distribution was calibrated by applying three constraints from the IPCC's Fourth Assessment Report: (1) a median equal to $3{ }^{\circ} \mathrm{C}$; (2) two-thirds probability that the equilibrium climate sensitivity lies between 2 and $4.5^{\circ} \mathrm{C}$; and (3) zero probability that it is less than $0{ }^{\circ} \mathrm{C}$ or greater than $10{ }^{\circ} \mathrm{C}$ (see Hegerl et al. 2006, p. 721).

The interagency group chose the calibrated Roe and Baker (2007) distribution from among the four candidates for two reasons. First, the Roe and Baker distribution is the only distribution that is based on a theoretical understanding of the response of the climate system to increased GHG concentrations (Roe and Baker 2007, Roe 2008). Second, of the distributions considered, it best reflects the IPCC judgment that "values substantially higher than $4.5{ }^{\circ} \mathrm{C}$ still cannot be excluded." It is also worth noting that while the Roe and Baker distribution puts a somewhat higher probability on the likelihood that the equilibrium climate sensitivity "is very likely larger than $1.5^{\circ} \mathrm{C}^{\prime \prime}$ (quoting from IPCC 2007), it is not inconsistent with the IPCC's statement.

Figure 2 illustrates how the calibrated Roe and Baker distribution compares to estimates of the probability distribution function of ECS in the empirical literature. M ore specifically, it overlays the calibrated Roe and Baker distribution on distributions estimated by the studies used to support the IPCC statement about likely values for ECS. ${ }^{12}$

\footnotetext{
${ }^{11}$ The four candidate probability distributions considered were R oe and Baker (2007), log-normal, gamma, and W eibull. Log-normal, gamma, and W eibull distributions are often used to characterize skewed, non-negative data.

${ }^{12} \mathrm{~T}$ he functions are scaled to integrate to unity between $0{ }^{\circ} \mathrm{C}$ and $10^{\circ} \mathrm{C}$.
} 
Figure 2: Comparison of Estimates of the Probability Density Function for Equilibrium Climate Sensitivity $\left({ }^{\circ} \mathrm{C}\right)$

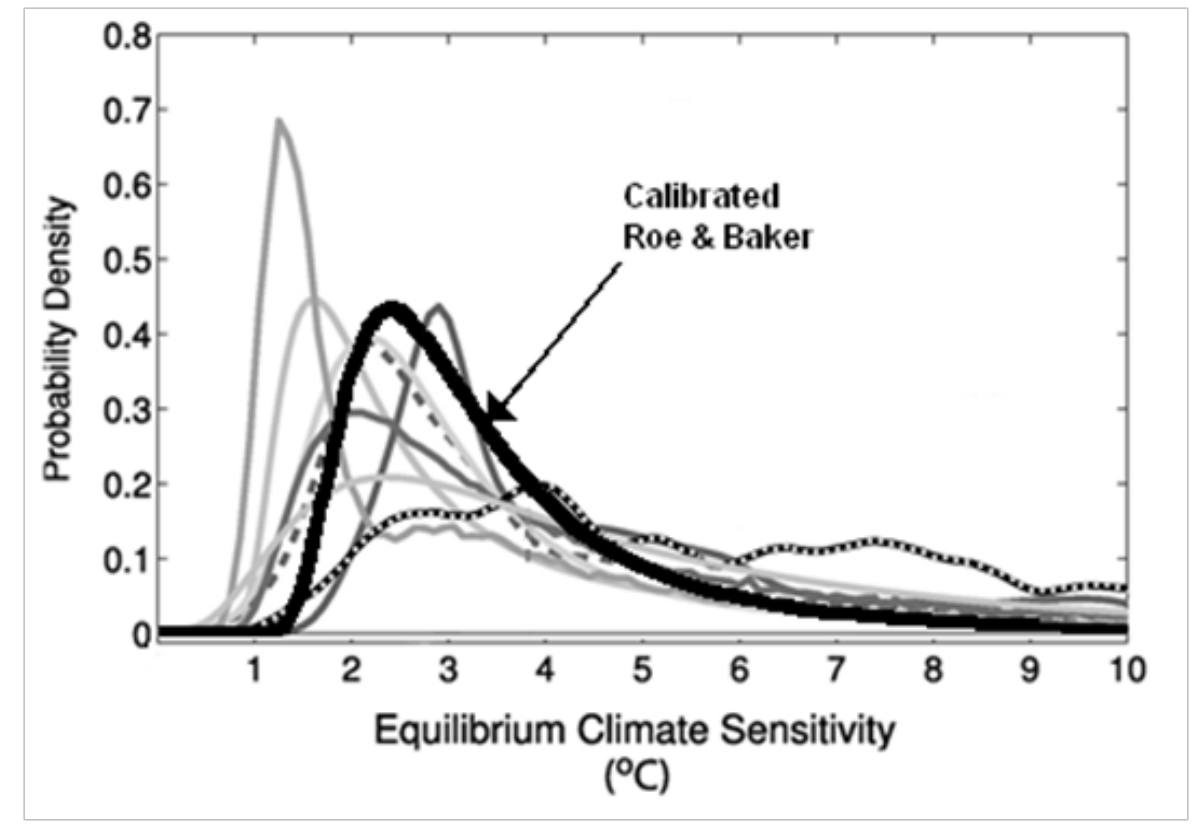

Source: Figure 9.20 from IPCC (2007) with the Roe and B aker distribution overlaid.

Notes: The calibrated Roe and Baker distribution has been included for comparison purposes.

\section{Discount Rates}

The discount rate is intended to reflect society's marginal rate of substitution between consumption in different time periods. To evaluate proposed U.S. government regulations that have both intra- and intergenerational effects, government agencies have traditionally used constant discount rates of 3 and 7 percent in their benefit-cost analyses (OM B 2003). However, the choice of a discount rate to be used over very long periods of time raises highly contested and exceedingly challenging scientific, economic, philosophical, and legal issues. As a result, there is 
no widespread agreement in the literature concerning the discount rates that should be used in an intergenerational context. ${ }^{13}$

Not surprisingly, discounting plays a critical role in determining the SCC estimates. To see this, note that the SCC is calculated by estimating the damages from an additional unit of $\mathrm{CO}_{2}$ emitted in a particular year in terms of reduced consumption due to the impacts of elevated temperatures in the future. Because $\mathrm{CO}_{2}$ has a half life of approximately 100 years, the damages from a unit of emissions occur over many decades. The discount rate is used to calculate the present value of the stream of damages in the year when the additional unit of emissions was released.

A rrow et al. (1996) outlined both descriptive and prescriptive approaches for determining the discount rate for climate change analysis. The descriptive approach reflects a positive perspective based on observations of people's actual choices (e.g., savings versus consumption decisions over time, allocations of savings among more and less risky investments). Advocates of this approach generally suggest inferring the discount rate from market rates of return since expenditures made today to mitigate GHG emissions are financed out of current consumption like any other investment. In contrast, the prescriptive approach reflects the normative judgments of the decision-maker (e.g., how interpersonal comparisons of utility should be made and how the welfare of future generations should be weighed against that of the present generation). M any advocates of this approach tend to argue for relatively low discount rates (e.g., Stern et al. 2006).

\footnotetext{
${ }^{13}$ For a detailed discussion of the factors the interagency group considered when selecting discount rates for the SCC, see the full interagency report. Portney and W eyant (1999) and Heal (2009) also discuss the challenges of intergenerational discounting.
} 
In the discussion that follows, we briefly outline the main factors that the interagency group considered when choosing particular discount rates.

U sing Historically O bserved Interest Rates

Although the interagency group found some appeal to relying on historically observed interested rates for discounting climate damages, in a world with heterogeneous returns to equities, gold, corporate bonds, and Treasury bills, which is the correct interest rate to use? The return on an investment made today in climate mitigation is reflected in the higher level of consumption available in the future due to reduced changes in climate (i.e., smaller temperature increases). This suggests that climate mitigation should be compared with standard public investments that increase the wellbeing of future generations; in fact, future generations would want the current generation to make investment choices in this manner.

Thus, the critical issue is how the returns to climate mitigation are correlated with the uncertain returns to investments in the overall economy, which are frequently proxied by overall equity returns. ${ }^{14}$ In this context, we need to consider three cases. The first case occurs when the returns to climate mitigation are perfectly correlated with the economy's overall growth rate, which would be the case if climate change damages are a fixed share of GDP. In this case, the proper discount rate is the expected return on investments in the economy as a whole. The second case occurs when the returns to climate mitigation investments are uncorrelated with the economy's overall growth rate. Here, the appropriate discount rate is the riskless interest rate. The third case

\footnotetext{
${ }^{14}$ The correlation between these climate mitigation investments and overall economy-wide growth can be viewed as the Beta in the capital asset pricing model, which measures how changes in market returns affect an individual investment's returns. B ecker, et al. (2011) and W eitzman (2007) provide insightful discussions of these issues.
} 
occurs when the returns to climate mitigation are negatively correlated with the economy's growth rate. For example, a climate mitigation project may generate positive returns when the overall economy is doing poorly and the marginal utility of an additional unit of consumption is especially high. In other words, these investments may have a low expected return but pay off when they are most valuable. In this case, it would be appropriate to use discount rates that are smaller than the riskless rate. Thus, the appropriate discount rate depends on an assumption about how the returns to climate mitigation investments correlate with the overall economy. However, there is no consensus on this issue in the literature.

\section{The Ramsey Equation}

The interagency group also found the representative agent discounting framework developed by Ramsey (1928) to be useful in its discussion of what discount rate to use for evaluating damages over long timeframes. This approach leads, under certain assumptions, to the Ramsey discounting formula, in which the interest rate at which future monetized damages are discounted equals the pure rate of time preference, ', plus the product of the growth rate of per-capita consumption, $g$, and the elasticity of marginal utility of consumption, $\cdot$. In other words, the social discount rate is equal to ${ }^{\prime}+\cdot{ }^{\prime} g .{ }^{15}$ Under this approach, the analyst applies either positive or normative judgments in selecting values for the key parameters ' and '.

The literature generally adopts values for - in the range of 0.5 to 3 , with a clustering around 2 (Szpiro 1986; Hall and Jones 2007; A rrow 2007; Dasgupta 2006, 2008; W eitzman 2007, 2009; and N ordhaus 2009). With respect to the pure rate of time preference, most articles in the climate

15 See U.S. EPA (2010a) for a general discussion of discounting concepts as they apply in an intergenerational context. 
change literature adopt values for ' in the range of 0 to 3 percent per year, and it is standard to assume rates of growth of consumption of around 2 percent in developed countries. ${ }^{16}$ Researchers that rely on empirical observations to inform their selection of these parameters may use discount rates as high as 5 or 6 percent, while researchers informed by the prescriptive approach often choose parameters that imply discount rates between 1 and 3 percent.

Uncertainty in the Discount Rate

A lthough the discount rate is an important driver of the benefits estimate, the interagency group also noted that it is uncertain over time. W eitzman (1998) showed theoretically and Newell and Pizer (2003) and Groom et al. (2006) confirmed empirically that discount rate uncertainty can have a large effect on net present values. A key result from these studies is that if the uncertainty in the discount rate is persistent (e.g., the rate follows a random walk ${ }^{17}$ ), then it will result in a certainty-equivalent ${ }^{18}$ discount rate that declines over time. Consequently, lower discount rates tend to dominate over the very long term (see W eitzman 1998, 1999). However, the issue of how to properly model discount rate uncertainty remains unresolved and continues to be an active area for research.

The Discount Rates Selected for Estimating the SCC

\footnotetext{
${ }^{16}$ The typically higher rates of growth in developing countries may help to explain their reluctance to make climate mitigation investments with payoffs that are several decades away (Deshpande and Greenstone 2010).

${ }^{17}$ This means that past behavior cannot be used to predict future behavior, which is why uncertainty cannot be resolved over time. There is no possibility of learning and improving one's predictions based on historical trends. ${ }^{18} \mathrm{~A}$ certainty-equivalent value is calculated by determining the discount rate at which an individual would accept a certain or known result over a potentially higher, but uncertain, result.
} 
Taking all of these factors into consideration, the interagency group ultimately chose three certainty-equivalent constant discount rates: 2.5 percent, 3 percent, and 5 percent per year. The two higher discount rates are principally informed by historically observed interest rates. The central value, 3 percent, is consistent with estimates in the economics literature as well as guidance from the Office of $M$ anagement and B udget (OM B 2003) concerning the consumption rate of interest. ${ }^{19} \mathrm{M}$ oreover, 3 percent roughly corresponds to the after-tax riskless interest rate. The upper value of 5 percent is included to represent the possibility that climate damages are positively correlated with market returns. In addition, this discount rate may be justified by the high interest rates that many consumers use to smooth consumption across periods. ${ }^{20}$

The low value, 2.5 percent, is included to reflect the concern that interest rates are highly uncertain over time. ${ }^{21}$ Furthermore, a rate below the riskless rate would be justified if climate investments were negatively correlated with the overall market rate of return. The use of the low (2.5 percent) value is also consistent with certain prescriptive judgments and ethical objections that have been raised about higher discount rates (see e.g., Stern et al. 2006; Stern 2008; Sterner and Persson 2008; Heal 2009).

\footnotetext{
${ }^{19}$ The consumption rate of interest is the rate one uses when current consumption mainly displaces future consumption, as opposed to also crowding out investment.

${ }^{20}$ To determine the post-tax riskless rate, the interagency group calculated the average real return from Treasury notes over the longest time period available (from Newell and Pizer 2003) and adjusted for Federal taxes (the average marginal rate from tax years $2003-2006$ is about 27 percent). This calculation produces a real interest rate of about 2.7 percent, roughly consistent with OM B Circular A-4's recommendation to use 3 percent to represent the consumption rate of interest. A measure of the post-tax risky rate for investments whose returns are positively correlated with overall equity market returns can be obtained by adjusting pre-tax rates of household returns to risky investments (approximately 7 percent) for taxes, yielding a real rate of roughly 5 percent.

${ }^{21}$ This value represents the average of the certainty-equival ent rates from the random walk approach and the meanreverting approach (in which over time, the discount rate tends to drift towards its long-term mean) used in Newell and Pizer (2003), starting at a discount rate of 3 percent. The calculations were done by W illiam Pizer using the original simulation program from N ewell and Pizer (2003).
} 


\section{G lobal versus Domestic SCC}

A nother important issue in estimating the SCC was whether to include damages that are projected to occur outside the United States. Current U.S. government guidance (OM B 2003) requires that economically significant regulations be analyzed from the domestic perspective. ${ }^{22}$ However, analysis from the international perspective is optional. The interagency group concluded that a global measure of the benefits from reducing U.S. emissions is preferable to a domestic measure because the climate change issue is highly unusual in at least two respects. First, it involves a global externality. That is, emissions of most GHGs contribute to damages around the world even if they are emitted in the United States. Consequently, to address the global nature of the problem, the interagency group concluded that the SCC should incorporate the full (global) damages caused by GHG emissions. Second, climate change is a problem that the U nited States cannot solve al one. Even if the United States were to reduce its GHG emissions to zero, it would be insufficient to avoid substantial damages from climate change.

\section{Utility Functions and E quity W eighting}

A nother modeling issue that needs to be addressed when quantifying the damages associated with a change in emissions is whether to employ "equity weighting" to aggregate changes in consumption across regions. Such weighting takes into account the relative reductions in wealth

\footnotetext{
${ }^{22}$ The development of a domestic SCC is greatly complicated by the relatively few region- or country-specific IA M s and even those that can produce a U.S.-only SCC are incomplete because they do not account for how damages in other regions could affect the United States (e.g., global migration, economic and political destabilization). Using a 2.5 or 3 percent discount rate, the U.S. benefit from reducing GHG emissions is, on average, about 7-10 percent of the global benefit across the scenarios analyzed with the FUND model. Viewing this issue in a different way, if the fraction of GDP lost due to climate change is assumed to be similar across countries, then the U.S. benefit would be proportional to the U.S. share of global GDP, which is currently about 23 percent. Note this value is highly speculative as there is no a priori reason why domestic benefits should be a constant fraction of net global damages over time.
} 
in different regions of the world (e.g., Anthoff, et al. 2009). For instance, a per-capita loss of $\$ 500$ in GDP would be weighted more heavily for a country with a per-capita GDP of $\$ 2,000$ than for a country with a per-capita GDP of $\$ 40,000$. In standard economics terms, this would be consistent with a declining marginal utility of income.

Due to both practical and theoretical challenges, the interagency group concluded that this approach would not be appropriate for estimating a SCC value for use in domestic regulatory analysis. First, such equity weighting would require the development of a global utility function. Second, a full accounting of the effects of a policy would have to consider the cost side of the equation: that the given cost of an emissions reduction imposes a greater welfare loss on a poor nation than on a wealthy one. ${ }^{23}$ Finally, explicitly using equity weighting in benefit-cost analysis, rather than conducting a separate distributional analysis, would be a departure from the U.S. government's standard operating procedure.

\section{CALCULATING AND SELECTING SCC VALUES}

To estimate SCC values for use in regulatory decision-making, the interagency group ran each of the three IAM models (DICE, PAGE, and FUND) using the common set of assumptions described in the previous section:

- A Roe and Baker distribution (2007) for the climate sensitivity parameter, calibrated to IPCC statements;

\footnotetext{
${ }^{23}$ Indeed, the use of equity weighting to reflect global differences in costs and benefits would greatly complicate a global cap and trade regime for pollution permits.
} 
- Five sets of GDP, population and carbon emissions trajectories based on the selected EM F-22 scenarios; and

- Constant annual discount rates of 2.5 percent, 3 percent, and 5 percent.

\section{Basic Computational Steps}

To ensure consistency across the three IAMs, climate damages were calculated as the lost consumption in each future year. The basic computational steps for calculating the SCC in a particular year $t$ are:

1. Enter the baseline path of emissions, GDP, and population ${ }^{24}$ and calculate the associated year-by-year paths of temperature and per capita consumption.

2. Shock the models with additional carbon emissions in year $t$ and recalculate the year-by-year paths of temperature and per capita consumption that result from the adjusted path of emissions in all years beyond $t$.

3. Compute the marginal damages in each year as the difference between the per capita consumption estimated in step 1 and step 2.

\footnotetext{
${ }^{24}$ To run each model through the year 2300 requires assumptions about GDP, population, GHG emissions, and radiative forcing trajectories after 2100 , the last year for which these projections are available from the EM F-22 models. These inputs were extrapolated from 2100 to 2300 as follows: (1) population growth rate declines linearly, reaching zero in the year 2200; (2) GDP/per capita growth rate declines linearly, reaching zero in the year 2300; (3) the decline in the fossil and industrial carbon intensity $\left(\mathrm{CO}_{2} / \mathrm{GDP}\right)$ growth rate over 2090-2100 is maintained from 2100 through 2300; (4) net land use $\mathrm{CO}_{2}$ emissions decline linearly, reaching zero in the year 2200; and (5) non- $\mathrm{CO}_{2}$ radiative forcing remains constant after 2100 .
} 
4. Discount the resulting path of marginal damages back to the year of emissions and calculate the SCC as a net present value.

These steps were repeated for each model out to 2050 to cover the time horizons anticipated for analysis of upcoming regulations. Because the climate sensitivity parameter is modeled probabilistically, and because PAGE and FUND incorporate uncertainty into other model parameters, the final output from each model run was a distribution of SCC values in year t. This exercise produced 45 separate distributions of the SCC for a given year (i.e., the product of 3 models, 3 discount rates, and 5 socioeconomic scenarios), which is clearly too many separate distributions to inform decision-making.

\section{Producing a Range of Plausible E stimates}

To produce a range of plausible estimates that still reflects the uncertainty in the estimation process, the distributions from each of the models and scenarios were weighed equally and combined to produce three separate probability distributions for the SCC in a given year, one for each assumed discount rate. For example, Figure 3 presents the distribution of SCC values in 2010 that are associated with a $3 \%$ discount rate and based on 150,000 model runs. To adequately sample the distribution of equilibrium climate sensitivities, each of the 15 modelsocioeconomic scenario pairs was run a total of 10,000 times, resulting in 5 th, 25 th, 50 th, 75 th, and 95 th percentile SCC values of $-\$ 9, \$ 4, \$ 14, \$ 28$, and $\$ 65$, respectively. 
Figure 3. Histogram of G lobal SCC E stimates in $2010\left(2007 \$ /\right.$ ton $\left.\mathrm{C}_{2}\right), 3 \%$ discount rate

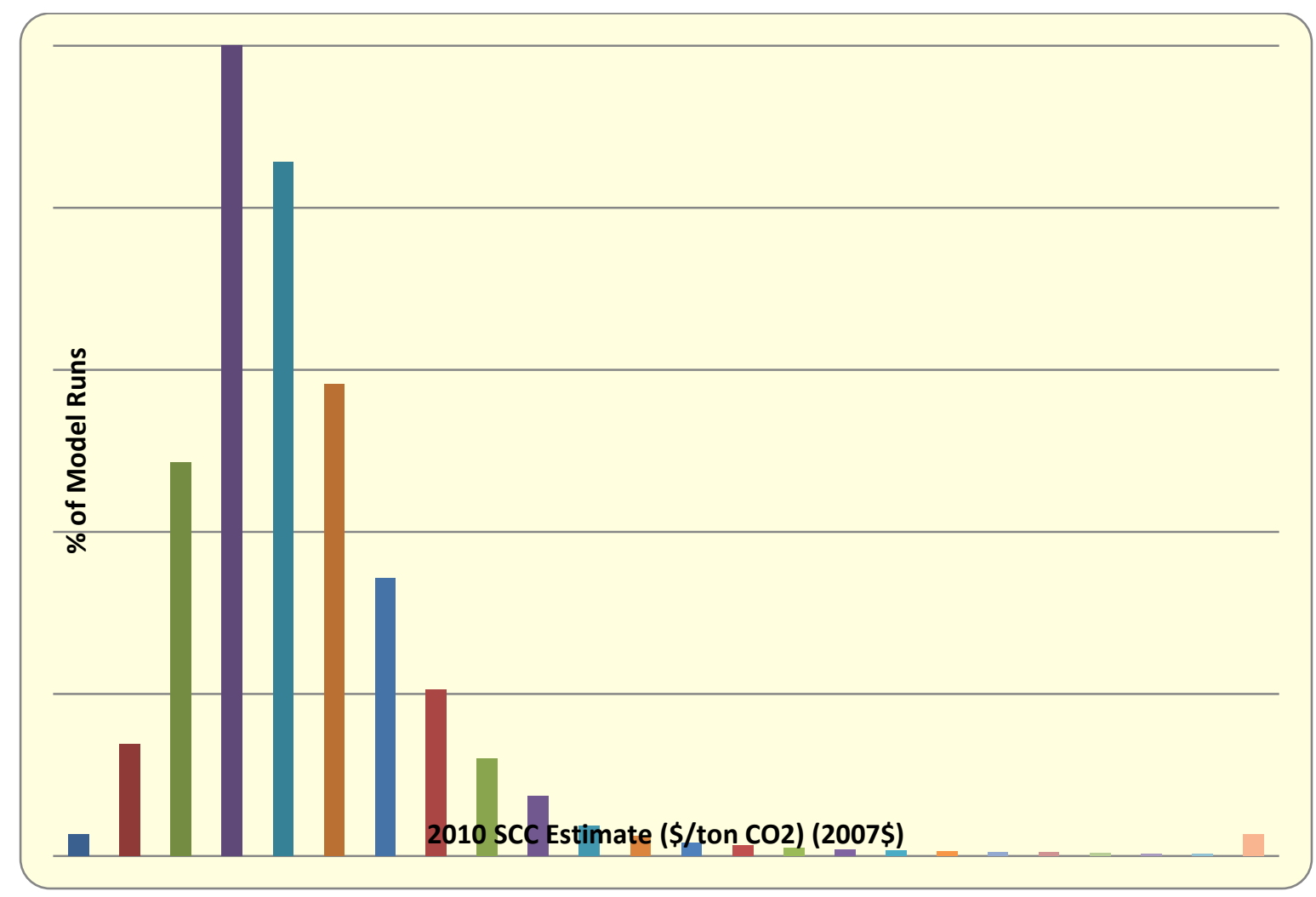

Source: DICE, PAGE, and FUND model runs used to generate interagency SCC values.

\section{Selecting Point Estimates for the SCC}

Four point estimates were selected from these distributions to represent the global SCC in a given year. Because the literature indicates that the $\mathrm{SCC}$ is quite sensitive to assumptions about the discount rate, but there is no consensus on the appropriate rate to use in an intergenerational context, the interagency group decided to calculate separate SCCs for each of the three discount rates. The central value is the average SCC across models and socio-economic and emissions scenarios at the 3 percent discount rate. The second and third values are the average SCC at the 2.5 percent and 5 percent discount rates, respectively. The interagency group also chose to 
include a fourth value to represent the possibility of higher-than-expected economic impacts from climate change (i.e., those that are further out in the tails of the SCC distribution), such as the possibility that the climate system is more sensitive to a doubling of $\mathrm{CO}_{2}$ than is represented by the models' damage functions at the mean climate sensitivity. Thus, for the fourth value, the group selected the SCC value for the $95^{\text {th }}$ percentile at a 3 percent discount rate. For 2010, the central value of the SCC is $\$ 21$ per ton of $\mathrm{CO}_{2}$ emissions, with sensitivity analysis to be conducted at $\$ 5, \$ 35$, and $\$ 65$. This last value is the SCC at the $95^{\text {th }}$ percentile for a 3 percent discount rate.

\section{Variability of the SCC Across Parameters and M odels}

Table 2 presents SCC estimates for 2010 by model, socio-economic scenario, and discount rate and illustrates the variability in the SCC across the input parameters. The discount rate is the assumption that has the largest effect on the SCC, with higher discount rates resulting in lower SCC values for each socio-economic trajectory. For example, the impact of the discount rate on FUND is especially evident in the 5 percent discount rate case where the mean SCC values are negative (i.e., there are benefits). Recall from Figure 1 that damages are negative in FUND for lower temperature increases. This means that because higher temperature increases do not occur until much further out in time, the discount rate effectively minimizes the influence of the years when there are damages relative to the years when there are benefits.

Table 2 al so indicates that there are measurable differences in the estimated SCC across the three models. FUND produces the lowest estimates, while PAGE generally produces the highest estimates. These results are qualitatively similar to the SCC values published in the literature, 
which are based on the latest versions of each model (e.g., see Nordhaus 2008, Hope 2008, and Hope 2006). ${ }^{25}$

The socio-economic scenarios have less impact on the SCC values than the other assumptions. Not surprisingly, when the model and discount rate are held constant, the SCC is generally the smallest with the $550 \mathrm{ppm}$ scenario. This is because the marginal ton of emissions occurs over the range of temperatures for which the damage functions in Figure 1 are at relatively low levels. In FUND, this results in a small negative number at the 3 percent discount rate. This differs from the results in the other models at least in part because, in contrast to DICE and PAGE, in FUND, increases in income over time decrease vulnerability to climate change (a form of adaptation).

\section{Key Differences in M odel Results}

Finally, Table 2 indicates that the SCC values are smaller under the M ERGE optimistic scenario than under the 550 ppm scenario for PAGE and DICE, but this is not the case for FUND. This highlights a key difference in the models that is not evident when examining the results for the other scenarios. Notably, climate damages are represented in DICE and PAGE as the loss of a fraction of gross economic output in each period, which is a function of only the temperature anomaly in that period. In contrast, the climate damages in FUND depend on both the period's temperature anomaly and the rate of temperature change. The interaction between these two effects can result in different rank ordering of scenarios with regard to incremental damages.

\footnotetext{
${ }^{25} \mathrm{H}$ owever, those values are not based on the same set of assumptions that were used by the interagency group. In particular, discount rates were not assumed to be constant over the entire time horizon.
} 
Table 2: Social C ost of $\mathrm{CO}_{2}$ E stimates for 2010 by M odel, Socio-E conomic T rajectory, and Discount Rate (in 2007 dollars)

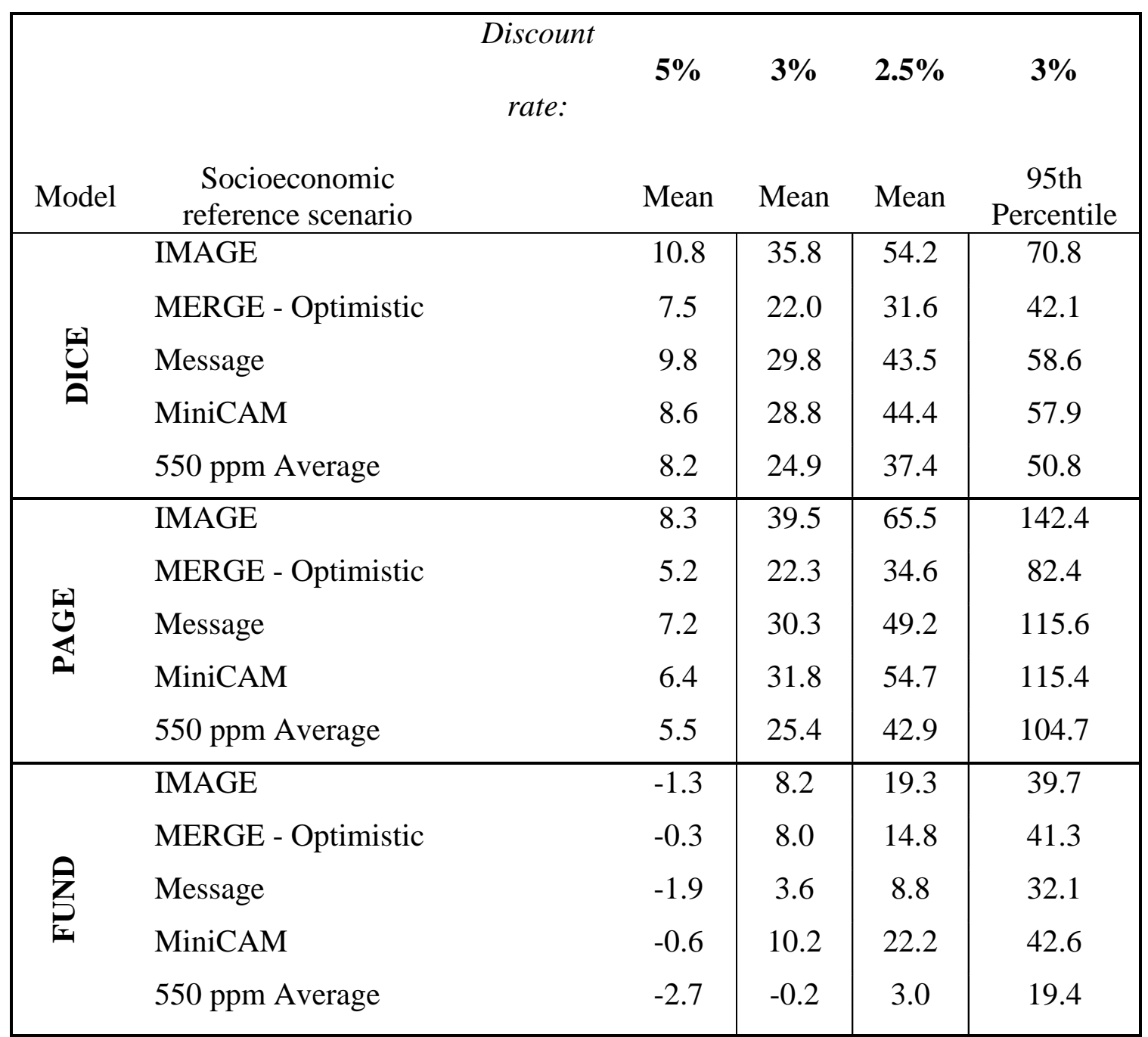

Source: Table 3, Interagency report.

\section{SC C V alues B eyond 2010}

The SCC values for years beyond 2010 were calculated in the same way as the values for 2010 , by combining all outputs (10,000 estimates per model run) from all scenarios and models for a 
given discount rate in each year. The four estimates of the SCC for emissions in 2025 are on average $\$ 30$ (using the 3 percent discount rate), $\$ 10$ (using the 5 percent discount rate), and $\$ 46$ (using the 2.5 percent discount rate), and $\$ 90$ for the $95^{\text {th }}$ percentile (using the 3 percent discount rate). Using the 5 percent, 3 percent, and 2.5 percent discount rates, the SCC values increase at annualized rates of 3.1 percent, 1.9 percent, and 1.6 percent, respectively, over the 2010-2050 period. ${ }^{26}$ The SCC increases over time because future emissions are expected to produce larger incremental damages as physical and economic systems become more stressed in response to greater climatic change.

\section{LIMITATIONS OF MODELS AND PRIORITIES FOR FUTURE RESEARCH}

The SCC estimates presented here incorporate the latest research across the relevant scientific and economic literatures. However, during the course of the modeling, it became clear that

several issues required additional exploration and research. ${ }^{27}$ This section discusses four key areas where there are gaps or limitations in current knowledge and identifies priorities for future research. The discussion is aimed at encouraging the development of updated and improved methods for estimating the SCC for use in future benefit-cost analysis of government regulations.

\section{Incomplete T reatment of Non-catastrophic I mpacts}

The incremental (i.e. non-catastrophic or gradually occurring) impacts of climate change are expected to be widespread, diverse, and heterogeneous. However, the magnitude of these impacts is uncertain because of the inherent complexity of climate processes, and uncertainties

\footnotetext{
${ }^{26}$ See the interagency report for the four SCC values in five-year increments from 2010 to 2050.

${ }^{27}$ For instance, a number of questions were raised regarding the form and inclusiveness of the economic damage function.
} 
concerning the economic behavior of current and future populations and the rate of technological change and adaptation. Although the IA M s used to estimate the SCC take a holistic approach, they cannot assign accurate values to all of the important physical, ecological, and economic impacts of climate change because precise information on the nature of damages is not always available, and even when it is, the models may lag behind the most recent research. M oreover, the models are calibrated over a relatively modest range of observed temperatures. Ocean acidification is one example of a potentially large but gradually occurring category of damages from $\mathrm{CO}_{2}$ emissions that is not currently captured by the IA M s. Incremental species and wildlife loss is another example of economic damage that is exceedingly difficult to monetize. $\mathrm{New}$ research is clearly needed to quantify and monetize these types of impacts.

\section{Incomplete Treatment of Potential C atastrophic I mpacts}

There has been considerable discussion recently concerning the risk of catastrophic impacts of climate change and how best to account for extreme scenarios, such as large releases of methane from melting permafrost and warming oceans. The damage functions underlying the three IA M S used to estimate the SCC vary in the degree to which they capture the economic effects of such climate change-induced "catastrophes" (M astrandrea 2009). In particular, the models' functional forms may not adequately capture:

- potentially discontinuous "tipping point" behavior in the Earth system;

- inter-sectoral and inter-regional interactions, including global security impacts of higher levels of warming; and

- limited near-term potential for substitutability between damages to natural systems and increased consumption. 
Tipping points. The damage functions in the IAMS are typically calibrated by estimating damages at moderate temperature increases (e.g., DICE is calibrated at $2.5^{\circ} \mathrm{C}$ ) and extrapolating to much larger temperature increases by assuming that damages increase as some power of the temperature change. However, recent science suggests that there are a number of potential climatic "tipping points" at which the Earth system may exhibit discontinuous behavior with potentially severe social and economic consequences (e.g., Lenton et al, 2008, K riegler et al., 2009). ${ }^{28}$

The implications of these tipping points have received increased attention in the economics literature. W eitzman (2009) suggests that catastrophic damages are extremely large- so large, in fact, that the damages from a low probability catastrophic event far in the future dominate the effect of the discount rate in a present value calculation and result in an infinite willingness-topay for mitigation today. However, others conclude that the conditions under which W eitzman's results hold are limited (N ordhaus 2009, Newbold and Daigneault 2009, Pindyck 2009). Given this difference in opinion, further research is needed before its practical significance can be fully understood and a reasonable approach developed to account for such risks in regulatory analysis.

Failure to incorporate inter-sectoral and inter-regional interactions. The damage functions underlying the three IAMS do not fully incorporate either inter-sectoral or inter-regional interactions. For instance, although most IAM s include damages to the agricultural sector, the effects of changes in the food supply on human health are not fully captured. Likewise, the

\footnotetext{
${ }^{28}$ It is important to note that crossing a climatic tipping point will not necessarily lead to an economic catastrophe in the sense used in the IAMs. A tipping point is a critical threshold beyond which some aspect of the Earth's system starts to shift into a qualitatively different state (for instance, one with dramatically reduced ice sheet volumes and higher sea levels). In the IAM S, a catastrophe is a low-probability environmental change that would have a high economic impact.
} 
effects of climate damages in one region on another region are not included in some models. A lthough difficult to quantify, these inter-regional interactions are the basis for climate-induced national and economic security concerns (e.g., Campbell et al., 2007; U.S. Department of Defense 2010) and are more likely at higher levels of warming.

Imperfect substitutability of environmental amenities. The IAMs assume it is possible to compensate for the economic consequences of damages to natural systems through increased consumption of non-climate goods. Although this is a common assumption in many economic models, in the context of climate change, it is possible that the damages to natural systems could become so great that no increase in consumption of non-climate goods would provide complete compensation, at least over the short- or medium-run (Levy et al., 2005; Sterner and Persson 2008).

\section{Incomplete Treatment of Adaptation and Technological Change}

Each of the three IAMs assumes a certain degree of adaptation. ${ }^{29}$ Climate change will also increase returns on investment to develop technologies that help individuals to cope with adverse climate conditions. For example, scientists may develop crops that are better able to withstand higher and more variable temperatures. Although DICE and FUND have calibrated their agricultural sectors under the assumption that farmers will change land use practices in response to climate change (M astrandrea, 2009), they do not take into account technological changes that

\footnotetext{
${ }^{29}$ For instance, the largest single benefit category from GHG mitigation in FUND is the lower electricity costs from reduced air conditioning usage (NRC 2009).
} 
lower the cost of this adaptation over time. Thus, more research is needed for the IAMs to adequately account for this directed technological change. ${ }^{30}$

\section{Treatment of $\mathbf{R}$ isk A version}

A key question that remained unanswered during the interagency process and demands further attention is what to assume about relative risk aversion with regard to high-impact outcomes. ${ }^{31}$ The SCC estimates do not account for the possibility that individuals may have a higher willingness to pay to reduce the likelihood of low-probability, high-impact damages than to reduce the likelihood of higher-probability, lower-impact damages that have the same expected cost. Anthoff et. al (2009) conclude that "the assumed rate of risk aversion is at least as important as the assumed rate of time preference (a component of the discount rate) in determining the social cost of carbon." ${ }^{32}$ This suggests that SCC estimates are also sensitive to assumptions about risk aversion. Nordhaus (2008) noted the need for further research on this issue in the context of climate change, including exploring the relationship between risk and income across models and the impact that uncertainty regarding various parameters has on the model results.

\section{CONCLUSIONS}

Benefit-cost analysis is an important tool for assessing policies that affect $\mathrm{CO}_{2}$ emissions, but it is not possible to adequately conduct such an analysis without a value for the social cost of carbon. The SCC enables us to monetize the economic value of the climate change-induced

\footnotetext{
${ }^{30} \mathrm{~A}$ full accounting of the benefits of this directed technical change would require accounting for the loss associated with reduced investment in areas that would otherwise have provided the highest expected returns.

${ }^{31}$ To our knowledge, the analysis of all other federal regulations assumes risk neutrality.

${ }^{32}$ Specifically, they used FUND to explore the sensitivity of the SCC to Ramsey equation parameter assumptions based on observed behavior.
} 
alterations in human health, ecosystems, agriculture and other facets of life that result from a marginal change in $\mathrm{CO}_{2}$ emissions, thus allowing us to compare the costs and the benefits of the avoided climate change associated with government policies. This makes it possible to more clearly distinguish between policies or regulations that have net benefits to society and those that have net costs.

This article has summarized the methodology used by a U.S. government interagency group to develop SCC values for estimating the incremental global benefits of the $\mathrm{CO}_{2}$ reductions associated with regulatory actions. These SCC values are the result of a technical and policy exercise designed to increase transparency and consistency in benefit-cost analyses of U.S. government regulations. This process and methodology can also serve as a model for future revisions and updates of the SCC estimates.

As discussed earlier, for 2010 , the central value of the SCC is $\$ 21$ per ton of $\mathrm{CO}_{2}$ emissions, with sensitivity analysis to be conducted at $\$ 5, \$ 35$, and $\$ 65$. The $\$ 5, \$ 21$, and $\$ 35$ values are averages calculated across a wide variety of models and scenarios for discount rates of 5,3 , and 2.5 percent, respectively. The $\$ 65$ value - the 95th percentile of the SCC distribution at a 3 percent discount rate- represents the potential for higher-than-expected impacts from temperature change. These SCC estimates grow over time based on rates endogenously determined within each model.

The SCC values described here have quickly become integrated into the evaluation of national policy choices in the United States. In the short time since their release, these SCC values have 
been used to monetize the $\mathrm{CO}_{2}$ emissions impacts of at least 16 major U.S. rules (those with costs or benefits above $\$ 100$ million in any given year) across several Federal agencies. The recent joint U.S. Department of Transportation-EPA standards for GHG emissions and fuel efficiency for light-duty vehicles in model years 2012-2016 (U.S. EPA 2010b) illustrate the impact that the SCC can have on regulatory decisions. The upfront technology costs of the GHG rule for light-duty vehicles are estimated to be approximately $\$ 350$ billion (in 2007 dollars) (U.S. EPA 2010b). B efore accounting for the impact of the rule on $\mathrm{CO}_{2}$ emissions, societal benefits which include the impact on energy security, refueling, local air pollutants, accidents, noise, and congestion - are estimated to be $\$ 280$ billion (U.S. EPA 2010b). Thus, before accounting for $\mathrm{CO}_{2}$ emissions, the proposed rule would have a net cost of nearly $\$ 70$ billion. ${ }^{33} \mathrm{However}$, when the value of the $\mathrm{CO}_{2}$ emissions reductions is incorporated into the benefit-cost analysis (using the interagency group's central SCC value), the proposed regulations are estimated to provide net societal benefits of more than $\$ 100$ billion.

The SCC values are also making their way into public hearings and court cases. For example, the SCC was used in a Colorado Public Utility Commission hearing regarding X cel's plan to retire 900 megawatts of coal-fired generation to comply with state law (K eohane 2010a). M ore recently, the SCC was included in a declaration before the U.S. Court of A ppeals for the District of Columbia Circuit regarding EPA GHG regulations (K eohane 2010b).

\footnotetext{
${ }^{33}$ We have excluded any assessment of private fuel savings resulting from the rule, because, although there is an emerging literature, many consider the question of how consumers account for fuel savings in their purchase decisions an unsettled empirical question (see Allcott and Greenstone 2012). Further, after accounting for the value of $\mathrm{CO}_{2}$ emissions (using the central SCC value), this rule's benefits exceed its costs without making an assumption about consumer's behavior.
} 
Looking to the future, research and modeling improvements are needed so that the SCC estimates used in regulatory analysis by the U.S. government continue to evolve and reflect current knowledge about the science and economics of climate impacts. Key areas for future research include improvements in how IA M s capture non-catastrophic and catastrophic impacts; increased focus on how predicted physical impacts translate into economic damages; a more complete treatment of behavioral assumptions concerning adaptation and technological changes that are induced by changing temperatures; analysis of how returns from investments in climate mitigation are correlated with investments in the economy overall; and development of appropriate methods for incorporating risk aversion. The role of the discount rate in regulatory analyses where the costs and benefits of a policy occur at different times also requires additional attention and discussion. A s revisions to the SCC are considered in the future, it is al so important to explore the sensitivity of the results to other aspects of the models (e.g. the carbon cycle). Finally, although most of the literature has focused on generating a social cost of carbon emissions, a methodology is also needed for valuing reductions in emissions of other GHGs. 


\section{References}

Allcott, H. and M. Greenstone. 2012. Is There an Energy Efficiency Gap? NBER Working Paper N o. 17766. http://www.nber.org/papers/w17766.

A nthoff D., C. Hepburn, and R. Tol. 2009. "Equity W eighting and the M arginal Damage Costs of Climate Change." Ecological Economics 68:836-849.

A rrow, K. 2007. "Global climate change: a challenge to policy." E conomist's Voice 4(3): A rticle 2.

A rrow, K., W. Cline, K. Mäler, M. Munasinghe, R. Squitieri, and J. Stiglitz. 1996. "Intertemporal equity, discounting and economic efficiency," in Climate Change 1995: Economic and Social Dimensions of Climate Change, Contribution of Working Group III to the Second Assessment Report of the Intergovernmental Panel on Climate Change.

Becker, Gary S., K evin M. M urphy, and Robert H. Topel. 2011. "On the Economics of Climate Policy." M imeograph.

Bianco, N., and F. Litz. 2010. Reducing Greenhouse Gas Emissions in the U nited States Using Existing F ederal Authorities and State Action. W orld Resources Institute. 
Bosetti V, E. Massetti, and M. Tavoni. 2007. "The WITCH model: structure, baseline, solutions."W orking paper. http://www.feem.it/Feem/Pub/Publications/ W Papers/ default.htm.

Campbell, K., J. Gulledge, J. M cN eill, J. Podesta, P.Ogden, L. Fuerth, J. W oolsey, A. Lennon, J. Smith, R. Weitz, and D. Mix. 2007. The age of consequences: The foreign policy and national security implications of global climate change. Center for Strategic \& International Studies.

Dasgupta, P. 2006. "Comments on the Stern Review's economics of climate change." University of Cambridge working paper.

Dasgupta, P. 2008. “Discounting climate change." J ournal of Risk and Uncertainty 37:141-169.

Deshpande, M., and M. Greenstone. 2010. "Comment on The Economics of Climate Policy," Berkeley Electronic J ournal of E conomic Analysis and Policy, 10(2)..

Groom, B., P. Koundouri, E. Panipoulou, and T. Pantelidis. 2006. "A n econometric approach to estimating long-run discount rates." J ournal of Applied Econometrics.

Hall, R., and C. Jones. 2007. "The value of life and the rise in health spending." Quarterly J ournal of E conomics 122(1):39-72.

Hansen, J., M. Sato, P. K harecha, G. Russell, D. W. Lea and M. Siddall. 2007. “Climate change and trace gases." Phil. Trans. Roy. Soc. A 365: 1925-1954. 
Heal, G. 2009. "Climate Economics: A Meta-Review and Some Suggestions for Future Research." Review of Environmental Economics and Policy, 3, 1: 4-21.

Hegerl, G., T. Crowley, W. Hyde, and D. Frame. 2006. "Constraints on climate sensitivity from temperature reconstructions of the past seven centuries." Nature 440.

Hope C. 2006. "The marginal impact of CO2 from PA GE2002: an integrated assessment model incorporating the IPCC's five reasons for concern." The Integrated Assessment J ournal 6(1):1956.

Hope C. 2008. "Optimal carbon emissions and the social cost of carbon under uncertainty." The Integrated Assessment J ournal 8(1):107-122.

Interagency Working Group on Social Cost of Carbon. 2010. Social Cost of Carbon for Regulatory Impact Analysis under Executive Order 12866. February. United States Government. http://www.whitehouse.gov/sites/default/files/omb/inforeg/for-agencies/Social-Cost-of-Carbonfor-RIA.pdf.

Intergovernmental Panel on Climate Change. 2007. "Summary for Policymakers." In Climate Change 2007: The Physical Science Basis, Contribution of Working Group I to the Fourth Assessment Report of the Intergovernmental Panel on Climate Change. Cambridge University Press. 
K eohane, N. 2010a. A nswer Testimony of $\mathrm{N}$ athaniel K eohane, In the M atter of Commission Consideration of Public Service Company of Colorado Plan in Compliance with House Bill 101365, "Clean A ir - Clean J obs A ct", D ocket N o. 10M -245E, September 17. http://www.dora.state.co.us/pls/efi/efi_p2_v2_demo.show document?p_dms document id=755 66.

K eohane, N. 2010b. Declaration to U nited States Court Of A ppeals For The District of Columbia Circuit, October 31. http://docs.nrdc.org/legislation/files/leg_10110401k.pdf .

K riegler, E., J. Hall, H. Held, R. Dawson, and H. Schellnhuber. 2009. "Imprecise probability assessment of tipping points in the climate system." Proc. Natl. Acad. Sci. 106: 5041-5046.

Lenton, T., H. Held, E. Kriegler, J. Hall, W. Lucht, S. Rahmstorf and H. Schellnhuber. 2008. "Tipping elements in the Earth's climate system." Proc. Natl. Acad. Sci. 105: 1786-1793.

Levy, M., S. Babu, and K. Hamilton. 2005. "Ecosystem conditions and human well-being." In: Ecosystems_and Human Well-being: Current State and Trends, Volume 1. [R. Hassan, R. Scholes, and N. A sh, eds.] W ashington: Island Press: 123-164.

M astrandrea, M. 2009. "Calculating the benefits of climate policy: Examining the assumptions of Integrated A ssessment M odels." Pew Center on Global Climate Change W orking Paper. 
M eehl, G., T. Stocker, W. Collins, P. Friedlingstein, A. Gaye, J. Gregory, A. Kitoh, R. K nutti, J. M urphy, A. Noda, S. Raper, I. Watterson, A. Weaver, and Z-C. Zhao 2007. "Global Climate Projections." in Solomon et al., Climate Change 2007.

National Research Council (NRC) 2009. Hidden Costs of Energy: Unpriced Consequences of Energy Production and U se. National A cademies Press.

Newbold S., and A. Daigneault. 2009. "Climate response uncertainty and the benefits of greenhouse gas emissions reductions." Environmental and Resource Economics 44:351-377.

Newell, R., and W. Pizer. 2003. Discounting the distant future: how much do uncertain rates increase valuations? J ournal of Environmental E conomics and M anagement 46: 52-71.

Nordhaus W. 2008. A Q uestion of Balance: Weighing the Options on Global Warming Policies. New Haven, CT: Y ale U niversity Press.

Nordhaus, W. 2009. "An Analysis of the Dismal Theorem. Cowles Foundation Discussion Paper. N o. 1686. J anuary.

Nordhaus W., and J. B oyer. 2000. Warming the World: Economic Models of Global Warming. Cambridge, M A: M IT Press. 
Office of Management and Budget (OMB). 2003. Circular A-4: Regulatory Analysis. September.

Pindyck, R. 2009. "Uncertain Outcomes and Climate Change Policy." NBER Working Paper, No. 15259. A ugust.

Portney, P., and J. Weyant (1999). Discounting and Intergenerational Equity. Resources for the Future. Edited V olume.

Roe, G. 2008. "Feedbacks, timescales, and seeing red." Annual Review of Earth and Planetary Sciences 37:5.1-5.23.

Roe, G., and M. Baker. 2007. "W hy is climate sensitivity so unpredictable?" Science 318:629632.

Stern N. 2008. "The economics of climate change." American E conomic Review 98(2):1-37.

Stern, N., et al. 2006. Stern Review: The Economics of Climate Change, HM Treasury, L ondon.

Sterner, T., and U. Persson 2008. "A n Even Sterner R eview: Introducing R elative Prices into the Discounting Debate." Review of Environmental Economics and Policy, 2, 1: 61- 76. 
Szpiro, G. 1986. "Measuring Risk Aversion: An Alternative Approach." The Review of Economics and Statistics 68(1): 156-9.

Tol, R. 2002a. "Estimates of the damage costs of climate change. Part I: benchmark estimates." Environmental and Resource Economics 21:47-73.

Tol, R. 2002b. "Estimates of the damage costs of climate change. Part II: dynamic estimates." Environmental and Resource Economics 21:135-160.

Tol, R. 2009. "An analysis of mitigation as a response to climate change." Copenhagen Consensus on Climate. Discussion Paper.

U.S. Department of Defense. 2010. Quadrennial Defense Review Report. February.

U.S. Environmental Protection Agency. 2010a. "Discounting Future Costs and Benefits" in Guidelines for Preparing E conomic Analyses. EPA 240-R-10-001.

U.S. Environmental Protection Agency. 2010b. Final Rulemaking to Establish Light-Duty V ehicle Greenhouse Gas Emission Standards and Corporate A verage Fuel Economy Standards. Regulatory Impact A nalysis. http://www.epa.gov/oms/climate/regulations/420r10009.pdf .

Weitzman, M. 2009. "On modeling and interpreting the economics of catastrophic climate change." Review of Economics and Statistics 91:1-19. 
Weitzman, M. 2007. "The Stern Review of the Economics of Climate Change." J ournal of Economic Literature 45, 3:703-724.

W eitzman, M. 1998. "Why the Far-Distant Future Should Be Discounted at Its Lowest Possible Rate." J ournal of Environmental E conomics and M anagement 36 (3): 201-208. 